\title{
Paving the way for a wider use of composites in railway industry
}

\author{
Impact of different flame retardants on the properties of epoxy resins
}

\author{
Sandra Gómez-Fernández ${ }^{1}$ (1) $\cdot$ Elena Jubete ${ }^{1} \cdot$ Blai López $^{2} \cdot$ Arsenio Navarro $^{2} \cdot$ Inma Roig $^{2} \cdot$ \\ Klaus Ritter ${ }^{3} \cdot$ Christof Storz $^{3} \cdot$ Nicolas Gogibus $^{3} \cdot$ Alaitz Rekondo $^{1}$
}

Received: 15 August 2018/Accepted: 26 April 2019/Published online: 13 May 2019

(c) The Author(s) 2019

\begin{abstract}
Different types of phosphorus containing halogen-free flame retardants (FRs) were added to an epoxy-dicyandiamide resin formulation in order to study to which extent they affect its glass transition temperature $\left(T_{\mathrm{g}}\right)$, tensile properties, thermal stability and burning behavior of the resin. For this purpose, an additive-type FR (ammonium polyphosphate encapsulated in melamine resin, MAPP) and two reactive-type FRs i) a commercial epoxy resin pre-reacted with 9,10-dihydro-oxa-10phosphaphenanthrene-10-oxide, (DOPO), and ii) a phosphorus containing hardener (poly(m-phenylene methylphosphonate), (PMP) were used. It was observed that the addition of additive-type FR did not affect in great extent the $T_{\mathrm{g}}$ and provided a V-0 rating in UL94 test at low loadings. The addition of reactive-type FRs (DOPO and/or PMP), however, modified the structure of the chain network resulting in lower crosslink density as a consequence of their higher equivalent mass, but achieving also with low PMP content V-0 rating.
\end{abstract}

Keywords Epoxy resin - Mechanical properties · Thermal properties · Thermal analysis

\section{Introduction}

Current European Union policies and actions are pushing toward globally competitive rail technology and services $[1,2]$. Much effort is being made to improve the performance of the rolling stock focusing on mass saving, cost-

Electronic supplementary material The online version of this article (https://doi.org/10.1007/s10973-019-08286-6) contains supplementary material, which is available to authorized users.

Sandra Gómez-Fernández

sgomez@cidetec.es

Elena Jubete

ejubete@cidetec.es

Blai López

blopez@aimplas.es

Arsenio Navarro

anavarro@aimplas.es

Inma Roig

iroig@aimplas.es

Klaus Ritter

klaus_ritter@huntsman.com efficiency and user-adaptability. The replacement of metallic parts of carbodies by fiber reinforced polymers (FRPs) seems to be a promising approach toward this objective.

The exceptional properties of epoxy resins make them stand out among polymeric materials. Epoxy matrices show mechanical strength, high adhesion to a variety of substrates, in addition to excellent heat, chemical and electrical resistance while allowing a significant mass reduction in the applications to which they are intended [3].

Christof Storz

christof_storz@huntsman.com

Nicolas Gogibus

nicolas_gogibus@huntsman.com

Alaitz Rekondo

arekondo@cidetec.es

CIDETEC, $\mathrm{P}^{\circ}$ Miramon 196, 20014 San Sebastian, Spain

2 Composites Department, AIMPLAS, Carrer de Gustave

Eiffel 4, 46980 Paterna, Spain

3 Huntsman Advanced Materials, Klybeckstrasse 200, 4057 Basel, Switzerland 
Apart from their use in a wide variety of everyday applications such as paints and coatings [4], epoxy resins can also be found in advanced applications such as high performance adhesives [5], anticorrosion coatings [6] and composites for electronic [7], biomedical [8], construction [7], maritime [9] and aerospace [10] industries. However, their presence has been limited in the railway industry due to the lack of studies, regulatory standards and requirements related to this family of materials. It is of special importance the fact that they also have to comply with the demanding fire, smoke and toxicity (FST) EN 45545 unified standard, which is related to fire protection on railway vehicles. This gap of knowledge hampers the substitution of the metallic parts of the carbody by this lightweight alternative that has the potential to keep the processing costs under competitive ranges.

The main drawback that hinders FRPs to comply with the EN 45545 standard is common for most of the existing polymers: a catastrophic fire behavior including not only their high flammability [11] but also the emission of toxic fumes such as carbon monoxide during combustion [12]. Their chemical structure based on carbon and hydrogen makes them potentially combustible and hazardous in a variety of scenarios where the presence of an ignition source and the oxygen available in the atmosphere could result in the development of a violent fire [13].

Therefore, the improvement in the fire-related properties of epoxy materials is critical to develop safe carbodies that are also able to endure the conditions supported by current metallic components.

A common strategy to improve the flame retardancy of polymeric materials has been the introduction of halogenated flame retardants (FRs) into their formulations [13]. Nevertheless, different studies found that these kind of compounds released toxic fumes during combustion that resulted to be potentially hazardous to human health. Such discovery, together with the increasing environmental concern about the role of halogenated compounds in the depletion of the ozone layer, has driven the scientific effort toward the replacement of halogenated FRs by eco-friendly alternatives.

In this scenario, the use of halogen-free phosphorus containing additive or reactive-type flame retardants is the two main approaches used to improve the flame retardancy of polymers and epoxy materials in particular [14]. Ammonium polyphosphate (APP) $[15,16]$ and alumina trihydrate (ATH) $[17,18]$ are the most used additive-type FRs in epoxy matrices, while phosphorus containing organic compounds such as 9,10-dihydro-oxa-10-phosphaphenanthrene-10-oxide (DOPO) $[19,20]$ and poly(mphenylene methylphosphonate) (PMP) $[21,22]$ are the most attractive among the reactive-type FRs due to their effectiveness at low concentration. Nevertheless, the major challenge regarding the use of FRs in the formulation of polymeric materials is to improve efficiently their flame retardancy without being detrimental for their thermal and mechanical properties. In view of the intended application of epoxy materials in structural parts in the railway sector, it is essential to maintain or even improve their good thermal and mechanical performance, such as glass transition temperature and thermal stability and mechanical resistance to the different external stresses affecting the carbody.

In this work, distinct additive and reactive-type halogenfree FRs were incorporated in the formulation of an epoxy resin, especially designed to be used as the matrix of composites for the railway industry. Different techniques such as Fourier transform infrared spectroscopy (FTIR), differential scanning calorimetry (DSC), thermogravimetric analysis (TGA), dynamic mechanical analysis (DMA), tensile tests and UL94 vertical burning test were used in order to study the impact of such FRs on the thermal and mechanical properties of the prepared materials, as well as to acquire a preliminary insight into their burning behavior.

\section{Experimental}

\section{Materials}

The commercially available prepreg resin system based on bisphenol A diglycidyl ether (DGEBA) Araldite $^{\circledR}$ LY 5150, Accelerator 1573 and Aradur 1571 from Huntsman Advanced Materials was used in a 100/2/11 mass ratio. The hardener Aradur 1571 consists of a dispersion of dicyandiamide (DICY) particles in epoxy resin. As flame retardant additive melamine microencapsulated phase II ammonium polyphosphate, MAPP (Exolit ${ }^{\circledR}$ AP 462, phosphorus content of $30 \%$ by mass) from Clariant was used. The formulations containing this additive required the use of a silicone-based deaerator (BYK-A 530) from BYK Additives \& Instruments in order to avoid the formation of bubbles in the resin plate. It was mixed with the resin components before adding Exolit ${ }^{\circledR}$ AP 462.

On the other hand, an epoxy resin pre-reacted with 9,10dihydro-9-oxa-10-phosphaphenanthrene 10-oxide (DOPO) (Polyphlox ${ }^{\circledR} 3742$, phosphorus content of $4 \%$ by mass) from Schill + Seilacher Struktol GmbH, and a phosphorus containing hardener, m-phenylene methyl phosphonate (PMP) from ICL-IP (Fyrol PMP, phosphorus content of $17.5 \%$ by mass) was used as reactive-type flame retardants. The samples containing PMP required the use of a catalyst (1-methylimidazole, designed as 1-MI, with purity $>99 \%$, Sigma-Aldrich), adding 0.5 parts per hundred of resin (phr) to the formulation. 
The chemical structures of the flame retardants are given in Online Resource 1. All the reactants were used as received, except for PMP and DOPO, which were previously melted in an oven at $130{ }^{\circ} \mathrm{C}$ for $1 \mathrm{~h}$.

\section{Sample preparation}

Briefly, the epoxy resin plates were prepared by weighing in a glass vessel the reactants and heating them up in an oil bath to $115^{\circ} \mathrm{C}$ to facilitate the dispersion and/or mixing of the flame owing to the high viscosity of the system. When the reactants reached $115{ }^{\circ} \mathrm{C}$ and were more fluent, they were carefully mixed to avoid the formation of bubbles with a mechanical stirrer at $500 \mathrm{rpm}$ during $10 \mathrm{~min}$. Then, the product was poured into a glass mold which had been previously coated with several layers of a demolding agent (Loctite ${ }^{\circledR}$ Frekote ${ }^{\circledR}$ from Henkel AG \& Co) and preheated at $140{ }^{\circ} \mathrm{C}$ in order to aid the filling of the mold. Finally, the mold was introduced in an oven and the resin samples were cured and postcured according to the conditions specified in Table 1, obtaining resin plates with dimensions of $190 \times 130 \times 4 \mathrm{~mm}^{3}$.

\section{Characterization}

The functional groups of the samples were identified by Fourier transform infrared spectroscopy (FTIR) using a Jasco FT/IR 4100 equipment with a GladiATR attenuated total reflectance accessory from PIKE Technologies. The epoxy samples were powdered with thin sandpaper, performing afterward 64 scans with a resolution of $4 \mathrm{~cm}^{-1}$ from 4000 to $400 \mathrm{~cm}^{-1}$.
The curing conditions and the glass transition temperature $\left(T_{\mathrm{g}}\right)$ were studied by differential scanning calorimetry (DSC) using a TA Instruments Discovery DSC 25 equipment. A first scan from 25 to $250{ }^{\circ} \mathrm{C}$ at a heating rate of $10{ }^{\circ} \mathrm{C} \mathrm{min}^{-1}$ was performed to around $5 \mathrm{mg}$ of uncured reactive mixture in order to calculate the curing enthalpy $\left(\Delta \mathrm{H}_{\mathrm{c}}\right)$. Then, according to the obtained curing onset temperatures, the samples were cured and postcured at the conditions specified in Table 1 . The $T_{\mathrm{g}}$ of the cured samples was also measured by DSC performing two scans from 25 to $250{ }^{\circ} \mathrm{C}$ at a heating rate of $10^{\circ} \mathrm{C} \mathrm{min}^{-1}$, calculating the $T_{\mathrm{g}}$ in the second scan.

The thermal behavior of the cured resin samples was studied by thermogravimetric analysis using a TA Instruments TGA Q500 equipment. Samples of $10 \mathrm{mg}$ were heated from 25 to $800{ }^{\circ} \mathrm{C}$ at a rate of $10{ }^{\circ} \mathrm{C} \mathrm{min}^{-1}$ under nitrogen purge $\left(60 \mathrm{~mL} \mathrm{~min}^{-1}\right)$.

Tensile properties were studied according to the ASTM D638-08 standard, testing 5-6 type V specimens (with thickness around $4 \mathrm{~mm}$ ) in an INSTRON 3365 universal testing machine in a room acclimated to $23{ }^{\circ} \mathrm{C}$. The crosshead rate was set at $1 \mathrm{~mm} \mathrm{~min}^{-1}$ to achieve a specimen breakage between 0.5 and $5 \mathrm{~min}$.

Dynamic mechanical analysis was performed with a TA Instruments Q800 DMA in single cantilever fixture with a span length of $17.5 \mathrm{~mm}$. The specimen size was $30 \times 13 \times 4 \mathrm{~mm}^{3}$, and the essay was carried out from 25 to $250{ }^{\circ} \mathrm{C}$ at a heating rate of $2{ }^{\circ} \mathrm{C} \min ^{-1}$. The oscillation amplitude and frequency were set at $7.5 \mu \mathrm{m}$ and $1 \mathrm{~Hz}$, respectively.

The flammability of the samples was measured according to the UL94 test for flammability of plastic materials for parts in devices and appliances-vertical

Table 1 Formulation and curing conditions of epoxy resin reference and flame-retarded epoxy samples

\begin{tabular}{|c|c|c|c|c|c|c|c|c|c|c|}
\hline & \multicolumn{8}{|c|}{ Reactants and additives/phr } & \multirow{2}{*}{$\begin{array}{l}\text { Curing T/ } \\
{ }^{\circ} \mathrm{C} / \mathrm{t}(\min )\end{array}$} & \multirow{2}{*}{$\begin{array}{l}\text { Postcuring } \\
\mathrm{T} /{ }^{\circ} \mathrm{C} / \mathrm{t} \text { (min) }\end{array}$} \\
\hline & LY 5150 & Aradur 1571 & Acc 1573 & MAPP & BYK A 530 & DOPO & PMP & 1-MI & & \\
\hline EP_REF & 100 & 11.00 & 2 & - & - & - & - & - & $140 / 60$ & $180 / 20$ \\
\hline EP_20AP & 100 & 11.00 & 2 & 20 & $0.5 \%$ & - & - & - & $140 / 60$ & $180 / 20$ \\
\hline EP_40AP & 100 & 11.00 & 2 & 60 & $0.5 \%$ & - & - & - & $140 / 60$ & $180 / 20$ \\
\hline EP_0.5PMP & 100 & 6.79 & 2 & - & - & - & 6.79 & 0.50 & $160 / 30$ & $180 / 40$ \\
\hline EP_1.0PMP & 100 & 6.79 & 2 & - & - & - & 14.00 & 0.50 & $160 / 30$ & $180 / 40$ \\
\hline EP_34DP & 100 & 15.83 & 2.69 & - & - & 34.51 & - & - & $160 / 30$ & $180 / 40$ \\
\hline EP_64DP & 100 & 19.95 & 3.28 & - & - & 63.99 & - & - & $160 / 30$ & $180 / 40$ \\
\hline EP_34DP_0.5PMP & 100 & 10.35 & 2.69 & - & $0.5 \%$ & 34.51 & 10.35 & 0.67 & $160 / 30$ & $180 / 40$ \\
\hline EP_34DP_1.0PMP & 100 & 10.35 & 2.69 & - & $0.5 \%$ & 34.51 & 20.70 & 0.67 & $160 / 30$ & $180 / 40$ \\
\hline EP_34DP_40AP & 100 & 15.83 & 2.69 & 40 & $0.8 \%$ & 34.51 & - & - & $160 / 30$ & $180 / 40$ \\
\hline EP_0.5PMP_40AP & 100 & 6.79 & 2 & 40 & $0.5 \%$ & - & 6.79 & 0.5 & $160 / 30$ & $180 / 40$ \\
\hline EP_1.0PMP_40AP & 100 & 6.79 & 2 & 40 & $0.5 \%$ & - & 14.00 & 0.5 & $160 / 30$ & $180 / 40$ \\
\hline
\end{tabular}


burning test, which was carried out to classify the resin samples according to their self-extinguishing character. Briefly, prior to testing, five specimens per sample with dimensions of $125 \times 12.7 \times 4 \mathrm{~mm}^{3}$ were conditioned in a climatic chamber at $23{ }^{\circ} \mathrm{C}$ and $50 \%$ relative humidity for $48 \mathrm{~h}$. A cotton indicator with dimensions of $50 \times 50 \times 6 \mathrm{~mm}^{3}$ was placed under the specimen in order to detect the presence of flaming drops or particles. The samples were burnt with a $50 \mathrm{~W}$ and $20 \pm 1 \mathrm{~mm}$ height flame for $10 \pm 0.5 \mathrm{~s}$, and the afterflame time was measured $\left(t_{1}\right)$. When the afterflame ceased, the sample was burnt again for additional $10 \pm 0.5 \mathrm{~s}$, and then, the afterflame time $t_{2}$ and the afterglow time $t_{3}$ were recorded. The samples were classified according to the specifications of the UL94 standard (Table 2).

\section{Results and discussion}

\section{Fourier transform infrared spectroscopy}

The functional groups present in the prepared FR containing epoxy plates were characterized by FTIR. Figure 1 shows the spectra of the FR additives and unmodified/pure epoxy system. The hardener Aradur 1571 shared with Araldite LY 5150 the characteristic signals of epoxy resins, since this hardener is constituted by a dispersion of DICY particles in epoxy resin. The following signals corresponded to characteristic vibration bands of DGEBA resin: O-H stretching $\left(3429 \mathrm{~cm}^{-1}\right)$ [23], C-H stretching of oxirane ring $\left(3050 \mathrm{~cm}^{-1}\right)$, aromatic $\mathrm{C}=\mathrm{C}$ and $\mathrm{C}-\mathrm{C}$ stretching vibrations (1608 and $1508 \mathrm{~cm}^{-1}$, respectively), aromatic $\mathrm{C}-\mathrm{O}$ stretching $\left(1182 \mathrm{~cm}^{-1}\right), \mathrm{C}-\mathrm{O}-\mathrm{C}$ stretching vibration from ether groups $\left(1030 \mathrm{~cm}^{-1}\right)$ and $\mathrm{C}-\mathrm{O}$ and $\mathrm{C}-\mathrm{O}-\mathrm{C}$ stretching vibrations from oxirane ring $\left(912\right.$ and $826 \mathrm{~cm}^{-1}$, respectively) $[23,24]$. The characteristic bands from DICY hardener corresponded to $\mathrm{NH}_{2}-$ and $\mathrm{N}-\mathrm{H}$ stretching vibrations overlapping with $\mathrm{O}-\mathrm{H}$ stretching (in the $3400-3100 \mathrm{~cm}^{-1}$ region), $\mathrm{N}-\mathrm{C} \equiv \mathrm{N}$ stretching vibrations from the different tautomers formed of DICY in solution with epoxy (2203 and $2158 \mathrm{~cm}^{-1}$ ) [25], C=NR stretching overlapped with $\mathrm{NH}_{2}$ deformation vibration $\left(1631 \mathrm{~cm}^{-1}\right)$ and $\mathrm{N}-\mathrm{C}=\mathrm{N}$ stretching vibration $\left(1564 \mathrm{~cm}^{-1}\right)$.

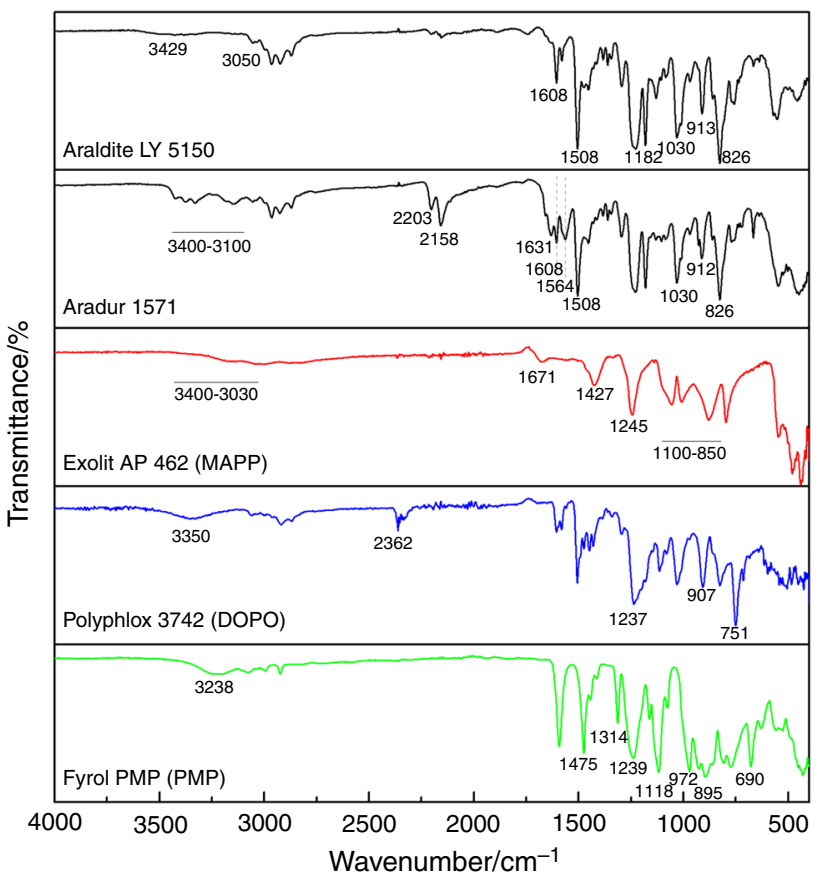

Fig. 1 FTIR spectra of raw materials used in FR epoxy samples

The FTIR spectra of the used flame retardants (Fig. 1) show the characteristic bands of different phosphorus containing functional groups. In case of melamine microencapsulated MAPP, $\mathrm{P}=\mathrm{O}$ stretching at $1245 \mathrm{~cm}^{-1}$ and $\mathrm{P}-\mathrm{O}-\mathrm{P}$ stretching vibrations in the region between 1100 and $850 \mathrm{~cm}^{-1}$ were observed and also the characteristic $\mathrm{NH}_{4}^{+}$asymmetric stretching signals in the $3400-3030 \mathrm{~cm}^{-1}$ region. Additionally, the signal attributed to the overlap of $\mathrm{C}=\mathrm{N}$ stretching and $\mathrm{NH}_{2}$ bending of the melamine coating was identified at $1427 \mathrm{~cm}^{-1}$, in accordance with Liu et al. [26]. On the other hand, DOPO prereacted epoxy FR presented in addition to the characteristic vibrations of epoxy, $\mathrm{P}=\mathrm{O}\left(1237 \mathrm{~cm}^{-1}\right)$ and $\mathrm{P}-\mathrm{O}-\mathrm{Ar}$ $\left(751 \mathrm{~cm}^{-1}\right)$ stretching vibrations. Additionally, the presence of a small peak attributed to $\mathrm{P}-\mathrm{H}$ stretching $\left(2362 \mathrm{~cm}^{-1}\right)$ and $\mathrm{P}-\mathrm{H}$ bending $\left(907 \mathrm{~cm}^{-1}\right)$ suggested the presence of adducts of unreacted DOPO [27]. Finally, in PMP spectrum the characteristic $\mathrm{P}=\mathrm{O}$ stretching band $\left(1239 \mathrm{~cm}^{-1}\right), \mathrm{O}-\mathrm{Ar}$ stretching in $\mathrm{P}-\mathrm{O}-\mathrm{Ar}\left(1118 \mathrm{~cm}^{-1}\right), \mathrm{P}-$ $\mathrm{O}$ stretching in $\mathrm{P}-\mathrm{O}-\mathrm{Ar}\left(972 \mathrm{~cm}^{-1}\right), \quad \mathrm{P}-\mathrm{CH}_{3}$ rock
Table 2 UL94 vertical burning test classification according to the criteria of the standard

\begin{tabular}{llll}
\hline Criteria & V-0 & V-1 & V-2 \\
\hline After-flame time for each specimen, $t_{1}$ or $t_{2}(\mathrm{~s})$ & $\leq 10$ & $\leq 30$ & $\leq 30$ \\
Total afterflame time, $t_{1}+t_{2}(\mathrm{~s})$ & $\leq 50$ & $\leq 250$ & $\leq 250$ \\
Afterflame plus afterglow time $\left(t_{2}+t_{3}\right)$ after second flame application & $\leq 30$ & $\leq 60$ & $\leq 60$ \\
Afterflame or afterglow of any specimen up to the holding clamp & No & No & No \\
Cotton indicator ignited by flaming particles or melt drops & No & No & Yes \\
\hline
\end{tabular}


$\left(895 \mathrm{~cm}^{-1}\right)$ and P-C stretching $\left(690 \mathrm{~cm}^{-1}\right)$ vibrations [21] were observed.

Figure 2 shows the IR spectra of the cured epoxy samples. The bands located at 3030 and $913 \mathrm{~cm}^{-1}$ assigned to oxirane ring vibrations disappeared confirming the reaction of the epoxy resin with the hardener. The presence of the flame retardants was evidenced by the characteristic bands of phosphorus. On the one hand, MAPP was identified in EP_40AP, EP_34DP_40AP and EP_0.5PMP_40AP by the characteristic $\mathrm{P}-\mathrm{O}-\mathrm{P}$ stretching vibration signal at $876 \mathrm{~cm}^{-1}$. On the other hand, the presence of DOPO in EP_64DP, EP_34DP_1.0PMP and EP_34DP_40AP was confirmed by the band at $751 \mathrm{~cm}^{-1}$ related to $\mathrm{P}-\mathrm{O}-\mathrm{Ar}$ stretching vibration. In contrast, the identification of PMP hardener in EP_1.0PMP, EP_34DP_1.0PMP and EP_0.5PMP_40AP was more difficult to discern due to the overlapping of $\mathrm{Ar}-\mathrm{O}-\mathrm{C}$ and $\mathrm{P}=\mathrm{O}$ stretching vibrations at $1239 \mathrm{~cm}^{-1}$ and the low intensity of the $\mathrm{P}-\mathrm{CH}_{3}$ rock vibration at $907 \mathrm{~cm}^{-1}$.

\section{Curing conditions and glass transition temperature}

The $\Delta \mathrm{H}_{\mathrm{c}}$ and $T_{\mathrm{g}}$ of the prepared materials were studied by DSC. $T_{\mathrm{g}}$ is an important parameter in epoxy resins and composites since it limits their application temperature, which is usually below $T_{\mathrm{g}}$. Figure $3 \mathrm{a}$ shows the thermograms of uncured sample mixtures, where the onset temperature and exothermic peaks related to the resin curing

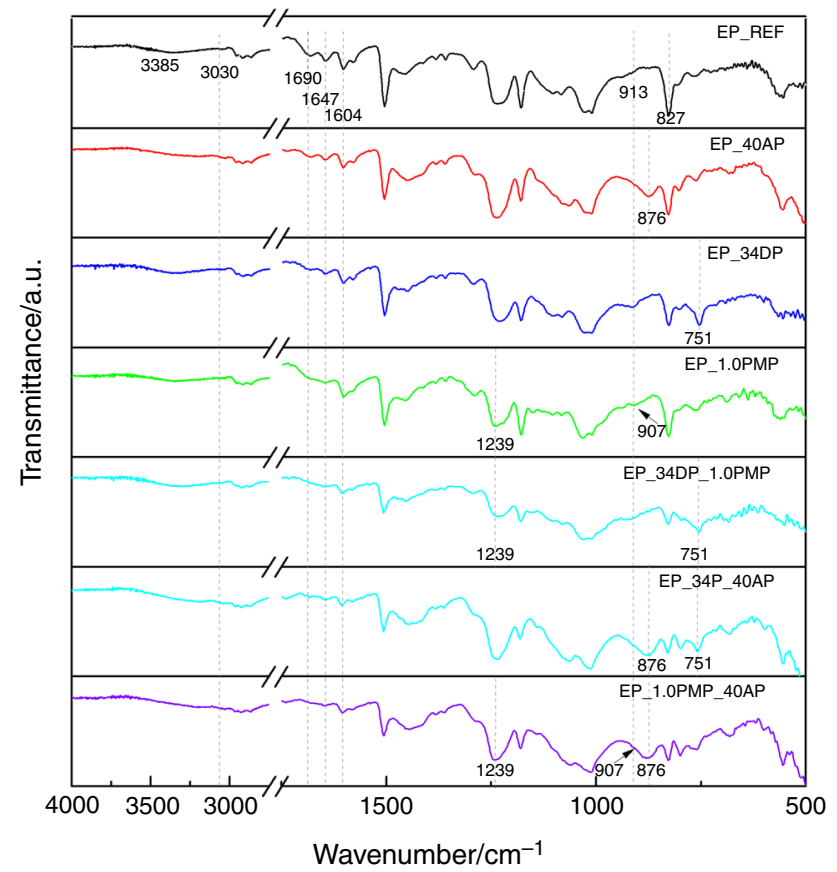

Fig. 2 FTIR spectra of representative samples of the cured epoxy plates process can be observed. Based on the measured curing onset temperatures, the reference and samples with MAPP were cured at $140{ }^{\circ} \mathrm{C}$ for $1 \mathrm{~h}$, whereas the samples containing DOPO and PMP, which showed higher curing onset temperatures, were cured at $160{ }^{\circ} \mathrm{C}$ for $30 \mathrm{~min}$. All the samples were then postcured at $180^{\circ} \mathrm{C}$ until the complete disappearance of the residual curing enthalpy. The curves of the completely cured materials are depicted in Fig. 3b, and the $\Delta \mathrm{H}_{\mathrm{c}}$ and $T_{\mathrm{g}}$ values after complete curing are given in Table 3.

The samples containing MAPP (EP_20AP, EP_40AP, EP_34DP_40AP, EP_0.5PMP_40AP and EP_1.0PM$\left.\mathrm{P} \_40 \mathrm{AP}\right)$ presented a decrease in $\Delta \mathrm{H}_{\mathrm{c}}$ with respect to EP_REF and proportional to their MAPP content. This was expected since increasing mass percentage of MAPP in the sample is linked to a reduction in the epoxy and hardener content. Thus, EP_20AP and EP_40AP experienced a reduction in the $\Delta \mathrm{H}_{\mathrm{c}}$ of 12.71 , and $28.77 \%$ with respect to EP_REF, coinciding closely with their MAPP content ( 15.03 and $26.14 \%$ by mass, respectively). The same behavior was observed in EP_34DP_40AP, which containing $20.72 \%$ by mass MAPP presented a $\Delta \mathrm{H}_{\mathrm{c}}$ decrease of $19.57 \%$ with respect to its analogue, EP_34DP.

Since MAPP did not participate in the crosslinking reaction, the $T_{\text {onset }}$ and $T_{\text {peak }}$ of the curing reaction remained nearly constant in EP_20AP and EP_40AP with respect to EP_REF. At low concentrations, MAPP had a reinforcing effect increasing slightly the $T_{\mathrm{g}}$ from 161 to $163{ }^{\circ} \mathrm{C}$ (comparing EP_REF to EP_20AP) due to interactions of polymeric chains with the particles of MAPP which contributed to decrease the free volume between chains hindering their mobility [16, 28]. However, at higher concentrations, MAPP had a plasticizing effect (in EP_40AP and EP_34DP_40AP) decreasing 10 and $13{ }^{\circ} \mathrm{C}$ the $T_{\mathrm{g}}$ compared to EP_REF and EP_34DP, respectively, as a consequence of the high filler content that exceeded the percolation threshold, which resulted in the formation of agglomerates [29].

On the other hand, the incorporation of DOPO pre-reacted epoxy reflected a decrease in $\Delta \mathrm{H}_{\mathrm{c}}$ and $T_{\mathrm{g}}$ comparing EP_34DP and EP_64DP to EP_REF, which is usual when introducing DOPO in epoxy formulations [30, 31]. This effect was attributed to the higher epoxy equivalent mass of the pre-reacted epoxy $\left(370 \mathrm{~g} \mathrm{Eq}^{-1}\right.$ in Polyphlox ${ }^{\circledR} 3742$ compared to $202.02 \mathrm{~g} \mathrm{Eq}^{-1}$ of Araldite ${ }^{\circledR} \mathrm{LY}$ 5150) which resulted in lower crosslinking [27, 32], being more pronounced with increasing DOPO content [22]. Additionally, the steric hindrance affected the temperature of maximum curing rate, $T_{\text {peak }}$, which was shifted toward slightly higher values $\left(10{ }^{\circ} \mathrm{C}\right.$ higher comparing EP_REF with EP_34DP and EP_64DP) in the presence of DOPO. The decrease in $T_{\mathrm{g}}$ was even more evident when incorporating $40 \mathrm{phr}$ MAPP (EP_34DP_40AP) as a consequence, as mentioned 
Fig. 3 DSC curves of the uncured reactive mixtures (a) and cured samples (b)
Table 3 Parameters related to epoxy curing obtained by DSC and crosslink density of the samples obtained by DMA (a)
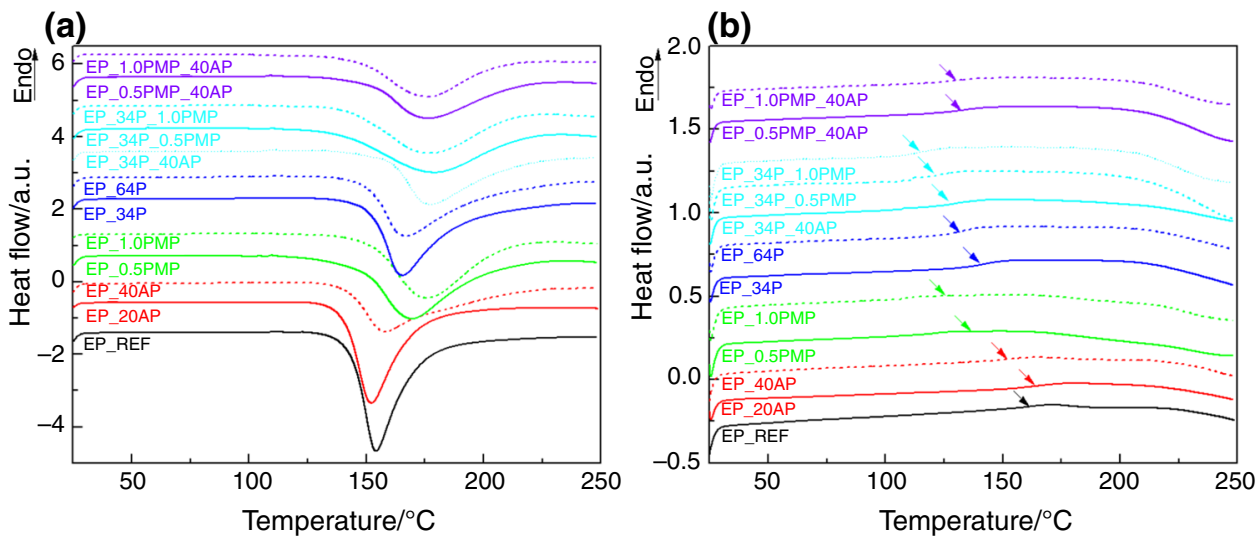

\begin{tabular}{|c|c|c|c|c|c|c|}
\hline \multirow[t]{2}{*}{ Sample } & \multirow[t]{2}{*}{ MAPP/mass $\%$} & \multicolumn{3}{|c|}{ Uncured reactive mixture } & \multirow{2}{*}{$\begin{array}{l}\text { Cured } \\
\text { sample } \\
T_{\mathrm{g} \propto} /{ }^{\circ} \mathrm{C}\end{array}$} & \multirow[t]{2}{*}{$v_{\mathrm{XL}}^{\mathrm{a}} \cdot 10^{3} / \mathrm{mol} \mathrm{cm}^{-3}$} \\
\hline & & $\begin{array}{l}\Delta \mathrm{H}_{\mathrm{c}} / \\
\mathrm{J} \mathrm{g}^{-1}\end{array}$ & $\begin{array}{l}T_{\text {onset }} / \\
{ }^{\circ} \mathrm{C}\end{array}$ & $\begin{array}{l}T_{\text {peak }} / \\
{ }^{\circ} \mathrm{C}\end{array}$ & & \\
\hline EP_REF & - & 434.19 & 144 & 154 & 161 & 2.58 \\
\hline EP_20AP & 15.0 & 379.02 & 141 & 152 & 163 & 3.75 \\
\hline EP_40AP & 25.5 & 309.29 & 142 & 158 & 151 & 4.15 \\
\hline EP_0.5PMP & - & 379.21 & 148 & 169 & 136 & 1.68 \\
\hline EP_1.0PMP & - & 355.04 & 152 & 175 & 126 & 1.34 \\
\hline EP_34DP & - & 386.27 & 152 & 165 & 141 & 1.85 \\
\hline EP_64DP & - & 365.70 & 151 & 167 & 131 & 1.08 \\
\hline EP_34DP_0.5PMP & - & 316.54 & 139 & 178 & 120 & 0.77 \\
\hline EP_34DP_1.0PMP & - & 299.43 & 145 & 175 & 115 & $\mathrm{nd}^{\mathrm{b}}$ \\
\hline EP_34DP_40AP & 20.7 & 310.67 & 108 & 176 & 128 & 2.29 \\
\hline EP_0.5PMP_40AP & 25.5 & 262.02 & 152 & 176 & 133 & 2.64 \\
\hline EP_1.0PMP_40AP & 25.5 & 242.25 & 147 & 176 & 130 & $\mathrm{nd}^{\mathrm{b}}$ \\
\hline
\end{tabular}

${ }^{\mathrm{a}} v_{\mathrm{XL}}$ : crosslink density calculated by DMA according to the theory of rubber elasticity

${ }^{\mathrm{b}}$ nd not determined

above, of overcoming the percolation threshold, increasing also the $T_{\text {peak }} 22{ }^{\circ} \mathrm{C}$ compared to EP_REF as a consequence of the steric hindrance of DOPO molecule.

In case of samples containing PMP, the $T_{\mathrm{g}}$ also decreased drastically (by $25{ }^{\circ} \mathrm{C}$ and $35^{\circ} \mathrm{C}$ compared EP_REF to EP_0.5PMP and EP_1.0PMP, respectively) as a consequence of lower crosslinking due to the higher equivalent mass of PMP $\left(90 \mathrm{~g}\left(\mathrm{Eq} \mathrm{H}^{+}\right)^{-1}\right)$ with respect to the hardener containing DICY Aradur 1571 (47.62 g (Eq $\left.\mathrm{H}^{+}\right)^{-1}$ ). The shift toward higher temperatures of $T_{\text {peak }}$ evidenced the lower reactivity of PMP which needed more temperature to complete the curing reaction, increasing by 15 and $25{ }^{\circ} \mathrm{C}$ the temperature of maximum curing rate when comparing EP_REF with EP_0.5PMP and EP_1.0PMP, respectively. The effect of the higher equivalent mass of Polyphlox ${ }^{\circledR} 3742$ DOPO and PMP was also observed when both additives were combined (EP_34DP_0.5PMP and EP_34DP_1.0PMP) leading to lower $T_{\mathrm{g}}$ values and higher $T_{\text {peak }}$ temperatures.
In contrast to EP_34DP_40AP, the addition of MAPP to EP_0.5PMP and EP_1.0PMP did not practically affect the $T_{\mathrm{g}}$ probably due to the better compatibility of the epoxy matrix containing phosphorus provided by PMP with MAPP.

\section{Thermal stability and preliminary fire behavior assess}

The thermal stability of epoxy resin samples was evaluated by TGA. Figure 4 shows the mass loss and derivative loss curves of the epoxy samples while Table 4 shows the $T_{\text {onset }}$ (temperature at 5\% mass loss) and maximum degradation rate temperatures for the first and second stage of decomposition ( $T_{\mathrm{d} 1}$ and $T_{\mathrm{d} 2}$, respectively), as well as the remaining residue at $800{ }^{\circ} \mathrm{C}$.

As it is well established, epoxy resins undergo pyrolytic degradation in one stage as a consequence of slow degradation and dehydration of the secondary alcohol [33] 
resulting in the release of low molecular weight fractions. In this particular case, the $T_{\text {onset }}$ of the reference epoxy took place at $344{ }^{\circ} \mathrm{C}$ and the maximum degradation occurred between 280 and $500{ }^{\circ} \mathrm{C}$ with a mass loss of $83.50 \%$, having the $T_{\mathrm{d} 1}$ at $381{ }^{\circ} \mathrm{C}$. In this stage, the epoxy resin decomposed by chain scission releasing low molecular mass volatiles such as water and phenolic compounds [34], leading to the formation of a carbonaceous char layer which left $16.50 \%$ residue at $800{ }^{\circ} \mathrm{C}$.

It was observed that the addition of MAPP altered the decomposition pathway of the epoxy via a mechanism that separated the decomposition in two differentiated stages. In the first stage, the decomposition of MAPP would give place to the release of water and ammonia together with the formation of polyphosphoric acid [35]. This acid would react with the hydroxyl groups of the reacted epoxy catalyzing its decomposition [36], shifting $T_{\mathrm{d} 1}$ in EP_20AP and EP_40AP $40{ }^{\circ} \mathrm{C}$ below the $T_{\mathrm{d} 1}$ of EP_REF and resulting in the carbonization of the polymer. Moreover, the melamine coating of the MAPP particles would act as a blowing agent by releasing ammonia during its decomposition. This gas would create a protective foamed char layer that would act as a heat shield that would further protect the material underneath from pyrolysis. The second stage of degradation took place between 400 and $500{ }^{\circ} \mathrm{C}$, and it was attributed to the decomposition of the unstable foamed char layer which by further crosslinking derived into a high-temperature stable char. Compared to EP_REF, the char formation increased up to a 82 and $96 \%$ when introducing 20 and $40 \mathrm{phr}$ MAPP to the epoxy, respectively.
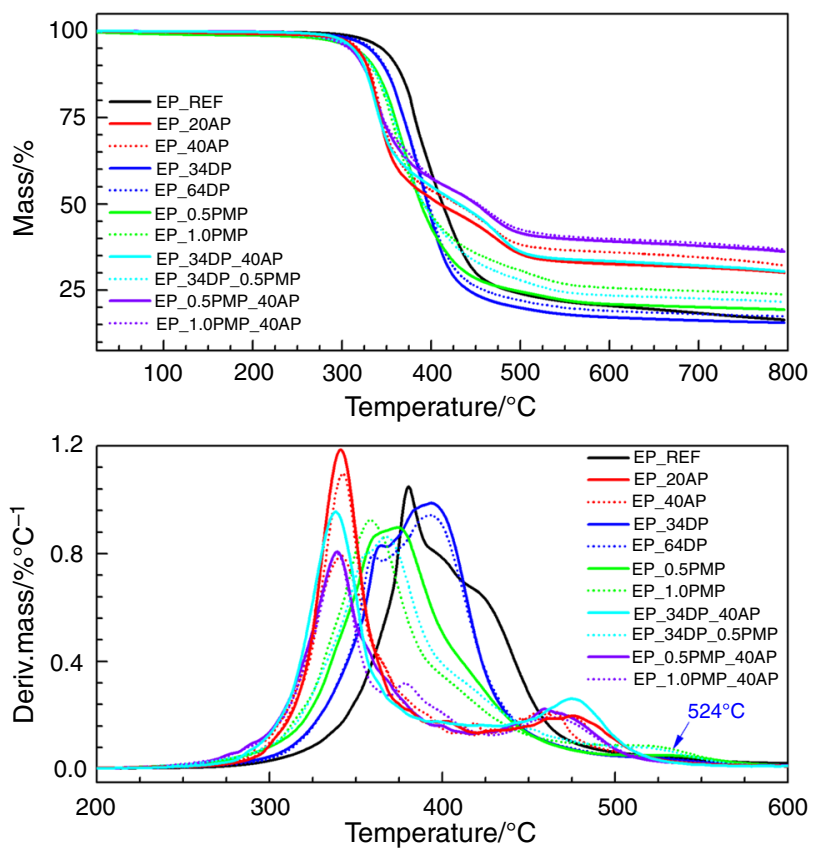

Fig. 4 Mass (up) and derivative mass (down) curves of the epoxy reference and the samples containing flame retardants
This condensed phase is characteristic of FR intumescent systems [37], which are constituted by an acid donor (in this case, the polyphosphoric acid from MAPP), a carbon donor (the epoxy chains) and a blowing agent (the melamine coating of MAPP), which in conjunction act catalyzing the decomposition of the polymer but forming a high amount of char residue to protect it from further decomposition. The same decomposition mechanism was observed in samples combining MAPP with DOPO or PMP (EP_34DP_40AP, EP_0.5PMP_40AP and EP_0.5PMP_40AP) compared to their respective unfilled samples (EP_34DP, EP_0.5PMP and EP_0.5PMP, respectively).

In regard to the effect of introducing DOPO in the epoxy formulation (EP_34DP and EP_64DP), a decrease in the $T_{\text {onset }}$ by 15 and $11{ }^{\circ} \mathrm{C}$ was registered, suggesting that the presence of phosphorus could have catalyzed the thermal degradation of the epoxy network, without altering its degradation mechanism [38, 39]. Notwithstanding, this decrease was also attributed to the lower crosslink density of the material [27]. On the other hand, the $T_{\mathrm{d} 1}$ was delayed $12{ }^{\circ} \mathrm{C}$ with respect to EP_REF probably due to the volatilization of the phosphorus-derived compounds. These effects, together with the subtle mass loss (below 5\%) at $524{ }^{\circ} \mathrm{C}$, which was attributed to the decomposition of unstable char enhanced by the presence of phosphorus at the early decomposition stages, suggested that the effect of DOPO is focused on the gas phase. As a matter of fact, it had practically no effect in the condensed phase since the residue values remained practically unaltered with respect to the control sample (EP_REF), as it was also observed by Mariappan et Wilkie [22].

On the other hand, the decrease in the $T_{\text {onset }}$ was more pronounced in the samples containing PMP. It decreased about $31{ }^{\circ} \mathrm{C}$ with respect to the reference evidencing along with the lower crosslink density, a change in thermosetting epoxy network. The amount of residue is higher than in EP_REF, 17 and 44\% in EP_0.5PMP and EP_1.0PMP, respectively, which is not as high as the residue of the samples containing MAPP. This could be due to the lower phosphorus content in these samples. Nevertheless, this evidence suggested that the stabilizing effect of PMP was also focused in the condensed phase.

A preliminary study of the flame retardant behavior of the samples was performed according to UL94 vertical burning test, which gives an insight at laboratory scale into the ignitability, flame spread and dripping behavior of polymers after the application of a pilot flame.

The results of the test are given in Table 4. As expected, the control sample (EP_REF) constituted by DICY-cured epoxy could not be rated according to UL94 standard due to its vigorous burning and the formation of tar and waxes.

Due to MAPP's high phosphorus content and the high amount of char formed during combustion, the addition of 
Table 4 Thermal stability results obtained from TGA and UL94 rating of the reference and flame retardant containing epoxy resins

\begin{tabular}{|c|c|c|c|c|c|c|c|c|}
\hline Sample & $T_{\text {onset }}^{\mathrm{a}} /{ }^{\circ} \mathrm{C}$ & $T_{\mathrm{d} 1}^{\mathrm{b}} /{ }^{\circ} \mathrm{C}$ & $\begin{array}{l}\text { Mass } \\
\operatorname{loss}_{1} 1 \%\end{array}$ & $T_{\mathrm{d} 2}^{\mathrm{b}} /{ }^{\circ} \mathrm{C}$ & $\begin{array}{l}\text { Mass } \\
\operatorname{loss}_{2} / \%\end{array}$ & $\begin{array}{l}\text { Residue at } \\
800{ }^{\circ} \mathrm{C} / \%\end{array}$ & $\begin{array}{l}\text { UL94 } \\
\text { rating }\end{array}$ & $\begin{array}{l}\text { Phosphorus } \\
\text { content/\% }\end{array}$ \\
\hline EP_REF & 344 & 381 & 83.50 & - & - & 16.50 & $\mathrm{NC}^{\mathrm{a}}$ & 0.00 \\
\hline EP_20AP & 316 & 341 & 51.69 & 475 & 18.23 & 30.08 & $\mathrm{~V}-0$ & 4.51 \\
\hline EP_40AP & 318 & 342 & 47.97 & 464 & 19.72 & 32.31 & $\mathrm{~V}-0$ & 7.84 \\
\hline EP_0.5PMP & 313 & 375 & 76.00 & 534 & 4.62 & 19.38 & $\mathrm{~V}-0$ & 1.00 \\
\hline EP_1.0PMP & 315 & 358 & 67.08 & 521 & 9.07 & 23.85 & $\mathrm{NC}^{\mathrm{c}}$ & 1.98 \\
\hline EP_34DP & 330 & 393 & 79.56 & 524 & 4.81 & 15.63 & $\mathrm{NC}^{\mathrm{c}}$ & 0.88 \\
\hline EP_64DP & 333 & 393 & 77.67 & 524 & 4.74 & 17.49 & $\mathrm{~V}-1$ & 1.37 \\
\hline EP_34DP_0.5PMP & 315 & 367 & 70.95 & 519 & 7.34 & 21.71 & $\mathrm{~V}-0$ & 2.01 \\
\hline EP_34DP_1.0PMP & 311 & 359 & 60.23 & 502 & 13.87 & 25.90 & $\mathrm{~V}-1$ & 2.96 \\
\hline EP_34DP_40AP & 313 & 338 & 47.10 & 475 & 22.51 & 30.39 & $\mathrm{~V}-0$ & 6.91 \\
\hline EP_0.5PMP_40AP & 309 & 340 & 44.03 & 464 & 19.79 & 36.18 & $\mathrm{~V}-0$ & 8.45 \\
\hline EP_1.0PMP_40AP & 308 & 340 & 46.55 & 464 & 16.64 & 36.81 & $\mathrm{~V}-0$ & 8.85 \\
\hline
\end{tabular}

${ }^{\mathrm{a}} T_{\text {onset: }}$ : Temperature at $5 \%$ mass loss

${ }^{\mathrm{b}} T_{\mathrm{d} 1,2}$ : Maximum degradation rate temperature in stage 1 or 2

${ }^{\mathrm{e}} N C$ Not classifiable

MAPP all alone or in combination with DOPO or PMP contributed to obtain a $\mathrm{V}-0$ rating even at $20 \mathrm{phr}$ loadings. This proved the effectiveness of the intumescent effect of melamine encapsulated MAPP, matching with TGA results. In case of DOPO containing samples, more than $1 \%$ phosphorus was needed to achieve a $\mathrm{V}-1$ rating due to its subtle condensed phase action which at least hindered dripping during combustion.

It was noteworthy that the addition of PMP resulted in better flame retardancy at lower content. In fact, the sample containing $1 \%$ phosphorus (EP_0.5PMP) presented V-0 rating in contrast with the sample with $1.98 \%$ phosphorus (EP_1.0PMP) which did not comply with the UL94 classification. This resulted to be somehow contradictory since several studies have determined that a $2 \%$ of phosphorus is needed to provide a $\mathrm{V}-0$ result in epoxy resins [22]. Notwithstanding, the flammability behavior is not only dependent on the phosphorus content but also depends on the nature of the epoxy resin and the hardener. In this case, the combination of DICY with PMP provided better flame retardancy in a $0.5 / 0.5$ mass $/$ mass ratio and higher $T_{\mathrm{g}}$ than 0.5/1.0 ratio. The 0.5/1.0 ratio of DICY/PMP led to lower crosslink density as it was already evidenced by DSC, which turned to be decisive to deteriorate the flame retardancy effect of the phosphorus present in PMP.

\section{Dynamic mechanical analysis}

Dynamic mechanical analysis (DMA) is a technique used to study and characterize the response of a material when it is subjected to a time-varying deformation. The response of the polymers is a combination of an elastic and a viscous constituent. The latter results in a delay of the response known as phase angle $\delta$ that allows to study the storage $\left(E^{\prime}\right)$ and loss $\left(E^{\prime \prime}\right)$ moduli, as well as the phase transitions occurring in the polymer. Figure 5 displays the evolution of $E^{\prime}$ with temperature from glassy to rubbery state of the epoxy materials. It was observed that all the FR containing samples presented higher modulus below $100{ }^{\circ} \mathrm{C}$ (Fig. 5a, c) owing to the increased rigidity provided by the phosphorus containing compounds that contributed to block segmental movements of the network. Above this temperature, the modulus of PMP and DOPO containing samples drops evidencing the higher mobility of the network due to their lower crosslink density. On the other hand, MAPP containing samples maintain their higher modulus up to $150{ }^{\circ} \mathrm{C}$ owing to the chain mobility constraints provided by solid MAPP particles.

In the presence of MAPP, the height of the $\tan \delta$ maximum (Fig. 5b, d) which represents the ratio of dissipated to stored energy did not vary to a great extent. On the other hand, when PMP and/or DOPO where used, maximum tan $\delta$ increased evidencing higher energy dissipation influenced by the lower crosslink density of the network. This observation suggested that the response to the applied force of MAPP containing samples was more elastic than those containing PMP or DOPO. This behavior was attributed to the lack of chemical interaction of MAPP particles with the matrix, confirming that MAPP did not participate in the crosslinking reaction and thus presenting similar crosslink densities than EP_REF [16]. In addition, the slight decrease observed in $\tan \delta$ height in the presence of MAPP 
(a)

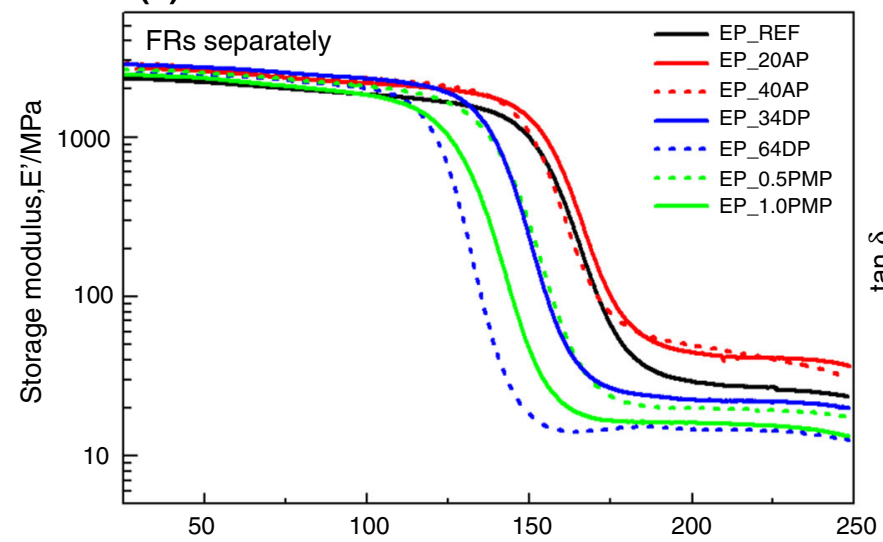

(c)

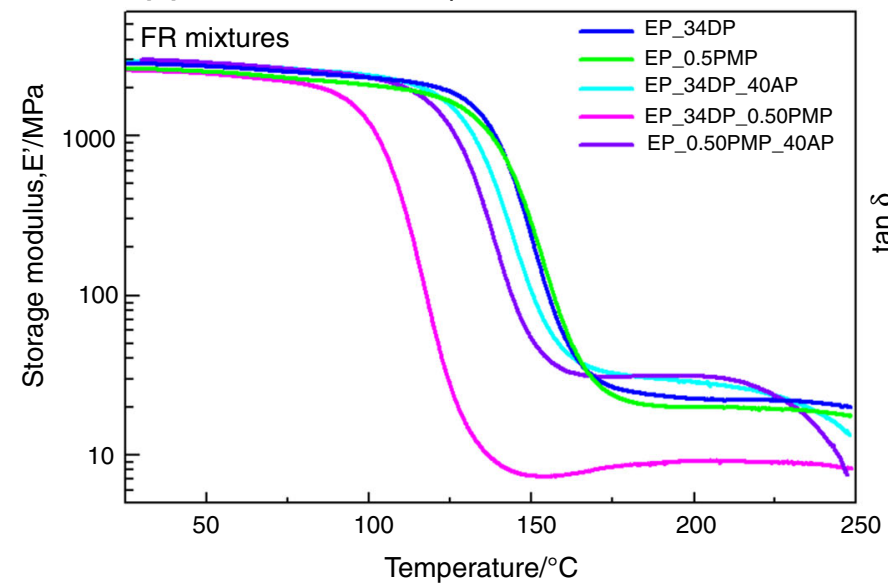

(b)

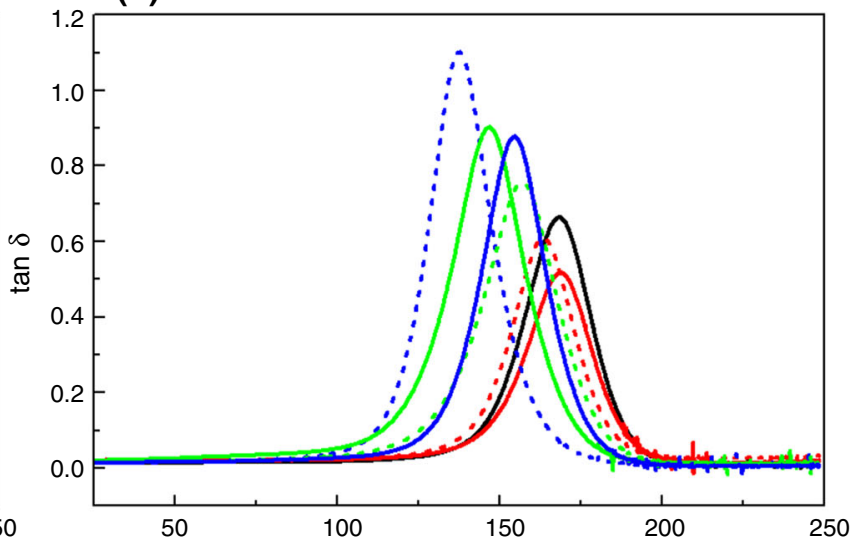

(d)

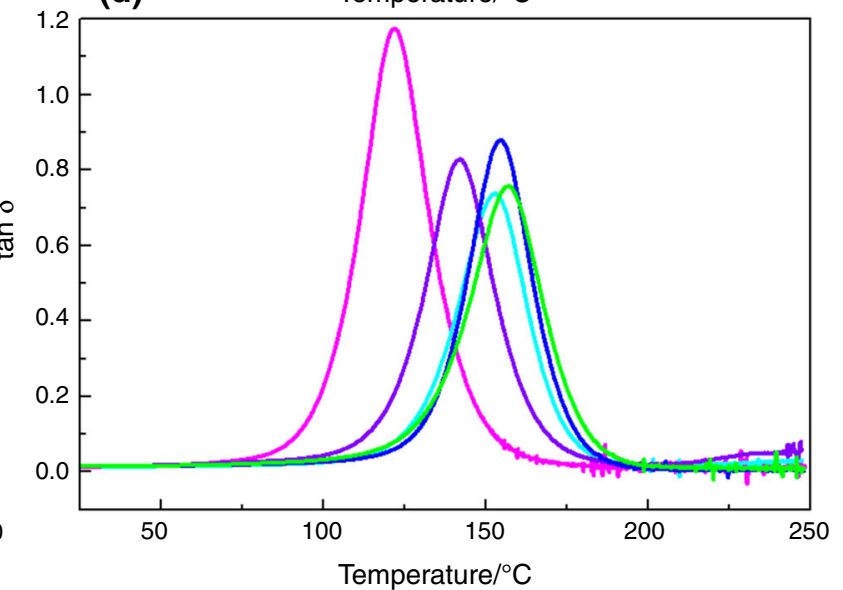

Fig. 5 Storage modulus (a, c) and $\tan \delta(\mathbf{b}, \mathbf{d})$ of the most representative epoxy samples

confirmed chain mobility restrictions due to the presence of solid fillers. The crosslink density $\left(v_{\mathrm{XL}}\right.$, Table 3$)$ was calculated correlating it with the storage modulus in the rubbery plateau according to the theory of rubber elasticity [40] (Eq. 1), where E' is the storage modulus $30^{\circ} \mathrm{C}$ above $T_{\mathrm{g}}, R$ is the gas constant and $T$ the absolute temperature.

$E^{\prime}=v_{\mathrm{XL}} R T$

When DOPO and/or PMP were used, the structure of the network changed owing to their higher equivalent masses and chemical nature, pointing out the lower crosslink density by lower $v_{\mathrm{XL}}$ and $\tan \delta$ values (lower $\tan \delta$ maximum temperature and higher $\tan \delta$ height), in accordance with the results obtained by DSC. In case of MAPP, $v_{\mathrm{XL}}$ values suggested fictitiously higher crosslink density due to the chain mobility restrictions occasioned by the solid additive particles. This resulted in higher $E^{\prime}$ values which affected the calculation of $v_{\mathrm{XL}}$.

\section{Tensile properties}

Tensile strength measurements were taken to analyze the effect of FRs on the mechanical properties (Table 5). As it is well established, the addition of the different FRs led to higher modulus and lower tensile strength values [15], as it was previously observed by increased storage modulus in DMA.

The poor interaction between the MAPP and the epoxy matrix was evidenced by the decreased tensile strength and strain at break, as well as by increased modulus $[15,16]$. In regard to tensile strength, it was found that it decreased by 29 and $42 \%$ when adding 20 and 40 phr MAPP to the resin, respectively. In the same way, the elongation at break also decreased by 47 and 59\%, respectively, as it can be observed in Fig. 6a. This effect was attributed to the poor interfacial bonding between the MAPP and the epoxy matrix, which could lead to the appearance of voids between the FR additive and the matrix, acting as stress concentration points. The same behavior was observed when combining MAPP with DOPO and PMP, in EP_34DP_40AP and EP_0.5PMP_40AP samples (Fig. 6b), 
Table 5 Tensile properties of epoxy resins with different FRs

\begin{tabular}{llll}
\hline Sample & Young's modulus/MPa & Tensile strength/MPa & Strain at break/\% \\
\hline EP_REF & $2359.3 \pm 91.8$ & $92.4 \pm 1.2$ & $8.81 \pm 0.27$ \\
EP_20AP & $2544.3 \pm 65.1$ & $65.2 \pm 2.5$ & $4.66 \pm 0.12$ \\
EP_40AP & $3123.5 \pm 97.4$ & $53.3 \pm 2.2$ & $3.65 \pm 0.30$ \\
EP_0.5PMP & $2512.3 \pm 11.2$ & $89.4 \pm 4.0$ & $7.36 \pm 0.41$ \\
EP_1.0PMP & $2487.2 \pm 2.9$ & $84.2 \pm 1.3$ & $5.98 \pm 0.35$ \\
EP_34DP & $2624.8 \pm 6.8$ & $90.8 \pm 1.0$ & $6.03 \pm 0.10$ \\
EP_64DP & $2723.8 \pm 57.4$ & $72.1 \pm 7.2$ & $3.82 \pm 0.59$ \\
EP_34DP_0.5PMP & $2708.8 \pm 48.5$ & $87.2 \pm 3.5$ & $5.00 \pm 0.41$ \\
EP_34DP_1.0PMP & $2955.1 \pm 61.3$ & $57.6 \pm 3.5$ & $2.71 \pm 0.27$ \\
EP_34DP_40AP & $3250.9 \pm 76.8$ & $63.2 \pm 4.1$ & $3.34 \pm 0.33$ \\
EP_0.5PMP_40AP & $3299.2 \pm 29.8$ & $64.1 \pm 2.1$ & $3.47 \pm 0.08$ \\
\hline
\end{tabular}

where the strain at break decreased to the same extent than EP_40AP, as well as the tensile strength, which value decreased a 30\% with respect to EP_34DP and a 28\% with respect to EP_0.5PMP, respectively.

Along with poor compatibility between filler and matrix, it is common to observe an increase in the values of the modulus owing to weak physical interactions (e.g, van der Waals interactions) between filler and matrix at low strains, which are enough to act as reinforcement in the system. This behavior was observed in all the samples containing MAPP. In fact, the modulus increased by 8 and $34 \%$ in EP_20AP and EP_40AP with respect to EP_REF, a $24 \%$ (a)

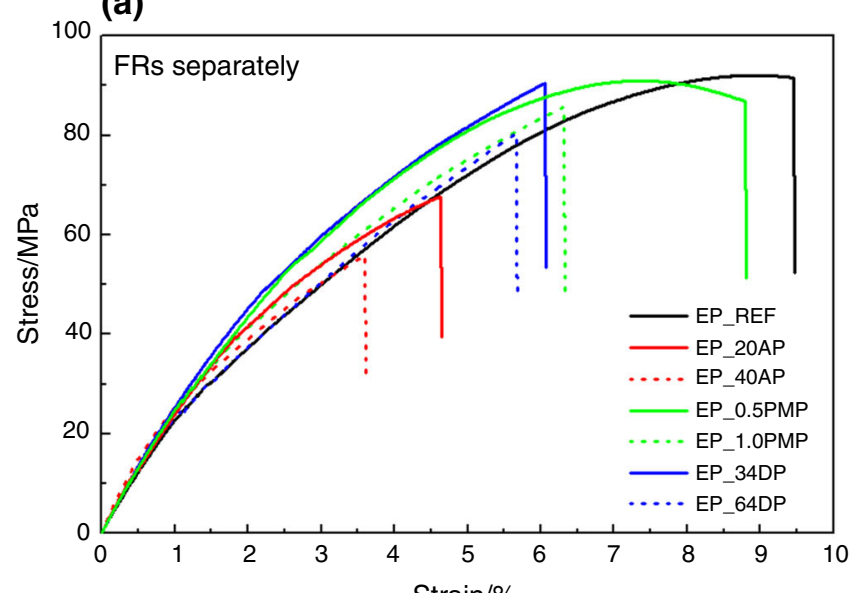

(c)

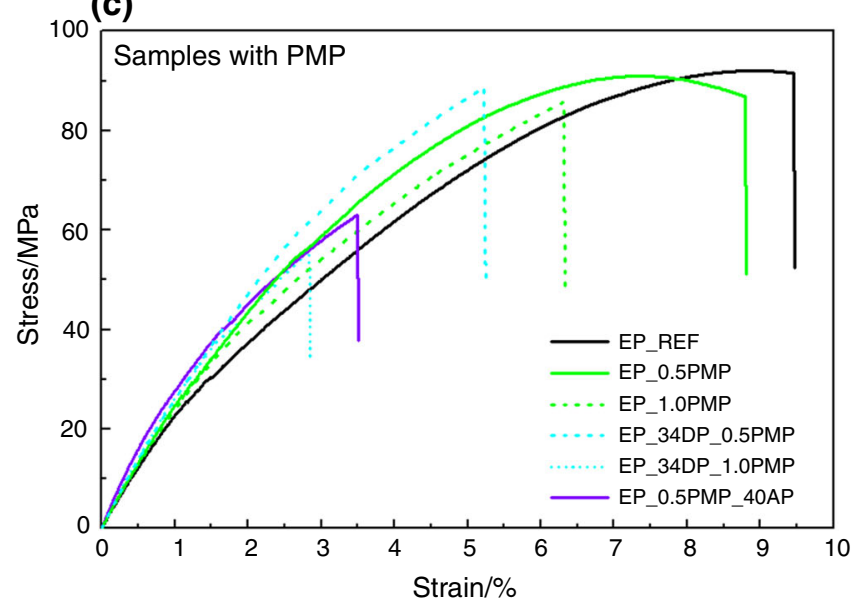

(b)

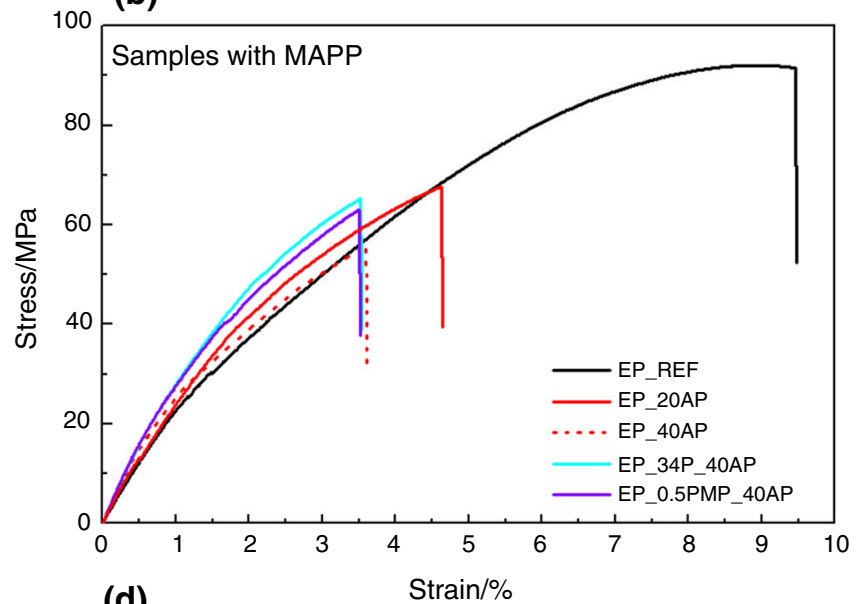

(d)

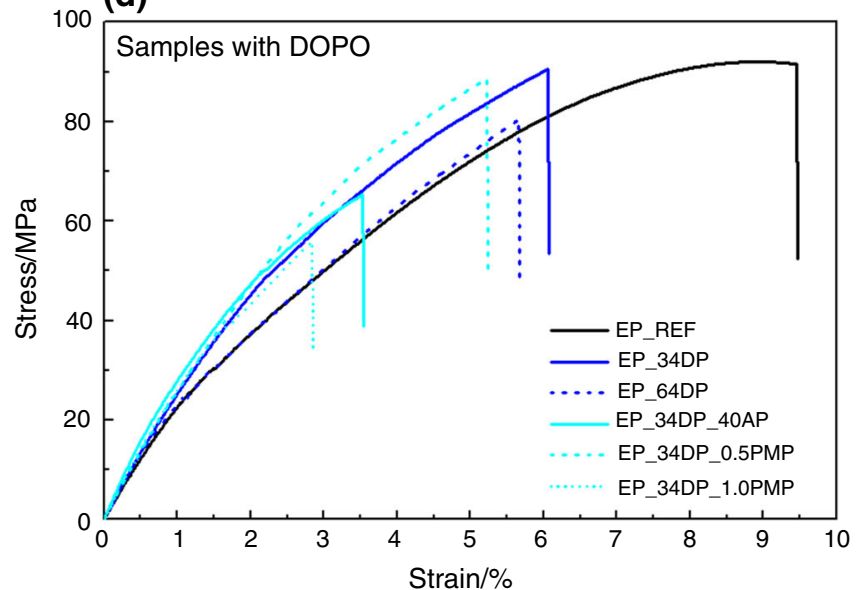

Fig. 6 Stress-strain curves of epoxy resins with the different flame retardants introduced independently in the formulation (a), and samples combining MAPP (b), PMP (c) and DOPO (d) with other FRs 
comparing EP_34DP with EP_34DP_40AP, and 27\% comparing EP_0.5PMP with EP_0.5PMP_40AP.

On the other hand, PMP containing samples EP_0.5PMP and EP_1.0PMP (Fig. 6c) presented the closest tensile properties to EP_REF. Focusing on the sample that achieved V-0 rating in UL94 vertical burning test, EP_0.5PMP, its modulus increased $6 \%$ with respect to EP_REF and tensile strength and strain at break decreased only 3 and $16 \%$, respectively. This formulation is the one with improved FR properties whose tensile properties were the least affected. This was attributed to the use as a hardener of PMP compound, which despite decreasing the $T_{\mathrm{g}}$ by $25^{\circ} \mathrm{C}$ due to its lower crosslinking respects the tensile behavior of the neat epoxy resin.

Alternatively, the samples containing DOPO (Fig. 6d), despite presenting better compatibility than MAPP with the matrix and lower crosslink density, resulted to be more rigid and brittle than EP_REF, especially with EP_64DP. This behavior is typical when introducing DOPO in the formulation owing to its rigid aromatic structure, as it was already observed by $\mathrm{Hu}$ et al. [19], who also determined that the optimal phosphorus content to achieve a V-0 rating and acceptable mechanical properties was 1.5 mass $\%$ reporting a decrease in tensile strength of $22 \%$. The same decrease in the mechanical strength was observed in EP_64DP containing 1.37 mass $\% P$, but in this case achieving a V-1 classification.

\section{Conclusions}

Different epoxy samples were prepared containing different types of flame retardants, an additive-type FR (MAPP) and two reactive-type FRs, a DOPO pre-reacted epoxy and a phosphorus containing hardener (PMP). In short, it was concluded that each FR had a distinct impact on the thermal and mechanical properties of the final epoxy resin.

In general, the use of the different FRs resulted in more rigid and brittle materials with improved flame retardancy. MAPP contributed to achieve V-0 rating in UL94 test with a loading of $20 \mathrm{phr}$ without affecting substantially the $T_{\mathrm{g}}$, but increasing in turn the elastic modulus and decreasing the fracture strain and tensile strength due to chain mobility constraints. On the other hand, PMP contributed to achieve $\mathrm{V}-0$ rating with only $1 \%$ phosphorus (EP_0.5PMP) maintaining the tensile properties close to reference sample, but decreasing the $T_{\mathrm{g}}$ due to its higher equivalent mass. Finally, DOPO containing samples required more than $1 \%$ phosphorus to provide a $\mathrm{V}-1$ result while decreasing $T_{\mathrm{g}}$ and increasing the rigidity and brittleness of the materials.

Taking into account that these promising results have been obtained with an epoxy resin intended for prepreg processing, and composite samples will be prepared and tested according to the EN 45545:2 standard for their further application in the railway industry. According to the obtained results, a careful selection of the FRs should be done based on the requirements of the material.

Acknowledgements This project has received funding from the Shift2Rail Joint Undertaking under the European Union's Horizon 2020 research and innovation programme under Grant Agreement No 777595 .

Open Access This article is distributed under the terms of the Creative Commons Attribution 4.0 International License (http://creative commons.org/licenses/by/4.0/), which permits unrestricted use, distribution, and reproduction in any medium, provided you give appropriate credit to the original author(s) and the source, provide a link to the Creative Commons license, and indicate if changes were made.

\section{References}

1. Gleave SD. Impact assessment study on the revision of institutional framework of the EU railway system, with a special consideration to the role of the European Railway Agency-Results of the stakeholder consultation. 2012.

2. European Commision. Mobility and Transport-Rail Research and Shift2Rail [Internet]. 2019. Available from: https://ec.europa. eu/transport/modes/rail/shift2rail_en.

3. Jin FL, Li X, Park SJ. Synthesis and application of epoxy resins: a review. J Ind Eng Chem. 2015;29:1-11.

4. Zeng W, Zhou Q, Zhang H, Qi X. One-coat epoxy coating development for the improvement of UV stability by DPP pigments. Dye Pigment. 2018;151:157-64.

5. Sousa JM, Correia JR, Cabral-Fonseca S. Durability of an epoxy adhesive used in civil structural applications. Constr Build Mater. 2018;161:618-33.

6. Tomić MD, Dunjić B, Likić V, Bajat J, Rogan J, Djonlagić J. The use of nanoclay in preparation of epoxy anticorrosive coatings. Prog Org Coat. 2014;77:518-27.

7. Fredi G, Dorigato A, Fambri L, Pegoretti A. Multifunctional epoxy/carbon fiber laminates for thermal energy storage and release. Compos Sci Technol. 2018;158:101-11.

8. Castañeda MT, Merkoçi A, Pumera M, Alegret S. Electrochemical genosensors for biomedical applications based on gold nanoparticles. Biosens Bioelectron. 2007;22:1961-7.

9. Tual N, Carrere N, Davies P, Bonnemains T, Lolive E. Characterization of sea water ageing effects on mechanical properties of carbon/epoxy composites for tidal turbine blades. Compos Part A Appl Sci Manuf. 2015;78:380-9.

10. Fiorina M, Seman A, Castanie B, Ali KM, Schwob C, Mezeix L. Spring-in prediction for carbon/epoxy aerospace composite structure. Compos Struct. 2017;168:739-45.

11. Martin FJ, Price KR. Flammability of epoxy resins. J Appl Polym Sci. 1968;12:143-58.

12. Hull TR, Stec AA, Lebek K, Price D. Factors affecting the combustion toxicity of polymeric materials. Polym Degrad Stab. 2007;92:2239-46.

13. Morgan AB, Gilman JW. An overview of flame retardancy of polymeric materials: application, technology, and future directions. Fire Mater. 2012;37:259-79.

14. Zhang W, He X, Song T, Jiao Q, Yang R. The influence of the phosphorus-based flame retardant on the flame retardancy of the epoxy resins. Polym Degrad Stab. 2014;109:209-17. 
15. Rajaei M, Wang DY, Bhattacharyya D. Combined effects of ammonium polyphosphate and talc on the fire and mechanical properties of epoxy/glass fabric composites. Compos Part B Eng. 2017;113:381-90.

16. Patrick Lim WK, Mariatti M, Chow WS, Mar KT. Effect of intumescent ammonium polyphosphate (APP) and melamine cyanurate (MC) on the properties of epoxy/glass fiber composites. Compos Part B Eng. 2012;43:124-8.

17. Könnicke D, Kühn A, Mahrholz T, Sinapius M. Polymer nanocomposites based on epoxy resin and ATH as a new flame retardant for CFRP: preparation and thermal characterisation. J Mater Sci. 2011;46:7046-55.

18. Weil ED, Levchik S. A review of current flame retardant systems for epoxy resins. J Fire Sci. 2004;22:25-40.

19. Hu J, Shan J, Wen D, Liu X, Zhao J, Tong Z. Flame retardant, mechanical properties and curing kinetics of DOPO-based epoxy resins. Polym Degrad Stab. 2014;109:218-25.

20. Perret B, Schartel B, Stöß K, Ciesielski M, Diederichs J, Döring $\mathrm{M}$, et al. Novel DOPO-based flame retardants in high-performance carbon fibre epoxy composites for aviation. Eur Polym J. 2011;47:1081-9.

21. Wu T, Piotrowski AM, Yao Q, Levchik SV. Curing of epoxy resin with poly(m-phenylene methylphosphonate). J Appl Polym Sci. 2006;101:4011-22.

22. Mariappan T, Wilkie CA. Flame retardant epoxy resin for electrical and electronic applications. Fire Mater. 2014;38:588-98.

23. González-González M, Cabanelas JC, Baselga J. Applications of FTIR on epoxy resins-Identification, monitoring the curing process, phase separation and water uptake. InTechOpen. 2012;13:261-84.

24. Nikolic G, Zlatkovic S, Cakic M, Cakic S, Lacnjevac C, Rajic Z. Fast fourier transform IR characterization of epoxy GY systems crosslinked with aliphatic and cycloaliphatic EH polyamine adducts. Sensors. 2010;10:684-96.

25. Gaukler JC. Oligomer formation in epoxy-dicyandiamide systems. J Adhes. 2012;88:720-50.

26. Liu G, Chen W, Yu J. A novel process to prepare ammonium polyphosphate with crystalline form II and its comparison with melamine polyphosphate. Ind Eng Chem Res. 2010;49:12148-55.

27. Wu Z, Li J, Chen Y, Wang Z, Li S. Effect of 9,10-dihydro-9-oxa10-phosphaphenanthrene-10-oxide on liquid oxygen compatibility of bisphenol a epoxy resin. J Appl Polym Sci. 2014;131:1-8.

28. Tang Q, Wang B, Tang G, Shi Y, Qian X, Yu B, et al. Preparation of microcapsulated ammonium polyphosphate, pentaerythritol with glycidyl methacrylate, butyl methacrylate and their synergistic flame- retardancy for ethylene vinyl acetate copolymer. Polym Adv Technol. 2014;25:73-82.
29. Barrau S, Demont P, Maraval C, Bernes A, Lacabanne C. Glass transition temperature depression at the percolation threshold in carbon nanotube-epoxy resin and polypyrrole-epoxy resin composites. Macromol Rapid Commun. 2005;26:390-4.

30. Yu D, Liu W, Liu Y. Synthesis, thermal properties and flame retardance of phosphorus-containing epoxy-silica hybrid resins. Polym Polym Compos. 2010;31:334-9.

31. Hou M, Liu W, Su Q, Liu Y. Studies on the thermal properties and flame retardancy of epoxy resins modified with polysiloxane containing organophosphorus and epoxide groups. Polym J. 2007;39:696-702.

32. Toldy A, Szlancsik Szolnoki B. Reactive flame retardancy of cyanate ester/epoxy resin blends and their carbon fibre reinforced composites. Polym Degrad Stab. 2016;128:29-38.

33. Levchik SV, Weil ED. Thermal decomposition, combustion and flame-retardancy of epoxy resins-a review of the recent literature. Polym Int. 2004;53:1901-29.

34. Grassie N, Guy MI, Tennent NH. Degradation of epoxy polymers: part 1-Products of thermal degradation of bisphenol-A diglycidyl ether. Polym Degrad Stab. 1985;13:11-20.

35. Camino G, Grassie N, McNeill IC. Influence of the fire retardant, ammonium polyphosphate, on the thermal degradation of poly(methyl methacrylate). J Polym Sci Polym Chem Ed. 1978;16:95-106.

36. Wang JS, Liu Y, Zhao HB, Liu J, Wang DY, Song YP, et al. Metal compound-enhanced flame retardancy of intumescent epoxy resins containing ammonium polyphosphate. Polym Degrad Stab. 2009;94:625-31.

37. Camino G. Flame retardants: intumescent systems. In: Pritchard $\mathrm{G}$, editor. Plastic additives (Polymer Science and Technology series). Dordrecht: Springer; 1998. p. 297-306.

38. Schartel B. Phosphorus-based flame retardancy mechanisms-old hat or a starting point for future development? Mater. 2010;3:4710-45.

39. Conley R, Quinn D. Retardation of combustion of phenolic, ureaformaldehyde, epoxy, and related resin systems. In: Lewin M, Atlas S, Pearce E, editors. Flame-retardant polym mater. New York: Plenum Press; 1975. p. 337-65.

40. Flory PJ, Rehner J. Statistical mechanics of cross-linked polymer networks I. Rubberlike elasticity. J Chem Phys. 1943;11:512-20.

Publisher's Note Springer Nature remains neutral with regard to jurisdictional claims in published maps and institutional affiliations. 